\title{
A TUTELA DA EVIDÊNCIA NO MANDADO DE SEGURANÇA EM MATÉRIA TRIBUTÁRIA
}

Douglas Mota

Antonio Carlos G. Gonçalves

\section{INTRODUÇÃO}

O Brasil, como se sabe, tem uma das maiores cargas tributárias do mundo. Estudos demonstram que os brasileiros pagam, em média, entre impostos, taxas e contribuições, o equivalente a um terço das suas rendas. Não bastasse isso, a burocracia e a dificuldade no cumprimento de obrigações relacionadas demandam elevado número de horas e, por vezes, implicam em equívocos não intencionais que levam a autuações que envolvem vultosas quantias.

Essa situação, entretanto, não chega a espantar. O nosso sistema tributário é, como demonstram vários estudos nacionais e internacionais, um dos mais complexos considerando as economias desenvolvidas. Apesar de ter sido criado para harmonizar as relações da sociedade de forma a atender aos seus princípios fundamentais (calcados, como consta da Carta Federal de 1988, na construção de uma sociedade livre, justa e solidária), o arcabouço das normas tributárias brasileiras está muito longe de se adequar a esses princípios, sendo, especificamente no que tange ao sistema tributário, muitas vezes uma forma de engessar as relações tributárias, dada a sua rigidez.

O desacerto entre o desejo arrecadatório dos entes tributantes e o dos contribuintes acaba produzindo uma infindável edição de normas tributárias, por vezes de dificílima interpretação, que atropelam os direitos individuais e coletivos, dado o não respeito aos princípios constitucionais. Nesse contexto, é de se destacar a 
importância do poder judiciário e a efetividade de suas decisões em matéria tributária, já que acabam sendo marco para aqueles que operam na defesa do direito dos contribuintes.

Contudo, no Brasil a morosidade do judiciário acaba sendo mais um empecilho para o apaziguamento das relações tributárias, na medida em que se torna não uma solução, mas parte do problema. Sob essa premissa é que há muito se busca no Brasil induzir celeridade ao processo tributário, o que inclusive pode auxiliar os entes públicos na arrecadação tributária e, quem sabe, evitar projetos de intenção duvidosa, como a securitização dos débitos em dívida ativa.

E, quando o assunto é efetividade, a atenção se volta para os denominados provimentos de natureza acautelatória e os seus possíveis efeitos práticos no dia a dia e nas atividades dos contribuintes, uma vez que têm como premissa a manutenção de forma célere do direito em risco, que, se alterado, poderá causar prejuízos irreversíveis à parte.

O Código de Processo Civil de 1973 (CPC/73), antes mesmo das reformas que sofreu ao logo da sua vigência, já previa a possibilidade de obtenção de provimentos dessa envergadura, ou seja, satisfativos, de algum modo e de maneira imediata. O seu texto original contemplava, como se sabe, a chamada medida cautelar, que tinha por objetivo a proteção do processo e a eficácia da decisão final.

Com o advento da Lei Federal n. 8.952/1994, houve a introdução, no ordenamento jurídico, da chamada tutela antecipada, por meio da qual havia a faculdade de o juiz, a requerimento da parte, antecipar, total ou parcialmente, os efeitos da tutela pretendida no pedido inicial. O Novo Código de Processo Civil (NCPC), não menos atento à importância do tema e com o intuito inclusive de aprimorá-lo, eliminou o processo cautelar e estabeleceu duas medidas de aplicabilidade imediata, que ficaram divididas nas denominadas tutelas de urgência e de evidência.

Essas figuras constam do Livro V - Tutela Provisória do NCPC. Segundo o art. 294 do referido diploma, a tutela provisória poderá fundamentar-se em urgência ou evidência, sendo que em ambos os casos poderá haver a concessão em caráter antecedente ou incidente (quando independerá do pagamento de custas). Como se pode observar, há clara distinção entre tutela de urgência (art. 300 a 310) e tutela de evidência (art. 311), com pressupostos diferentes. Em resumo, enquanto na primeira há urgência na proteção do direito, na segunda o que se tem em mente é acelerar a discussão.

Apesar de não ser o foco do presente artigo, a nosso ver se mostra importante deixar clara a distinção entre as duas figuras. 


\subsection{Tutela de urgência}

A premissa aqui é simplesmente que as partes envolvidas não podem esperar a sentença final, uma vez que haveria situação de iminente risco, e aguardar a conclusão da análise do mérito poderia trazer prejuízo irreversível.

Segundo o art. 300 do NCPC, a tutela de urgência será concedida quando houver elementos que evidenciem a probabilidade do direito e o perigo de dano ou o risco ao resultado útil do processo. Ou seja, como esclarece Cassio Scarpinela Bueno, "São expressões redacionais do que é amplamente consagrado nas expressões latinas fumus boni iuris e periculum in mora, respectivamente". Para a concessão da medida acautelatória o juiz pode, conforme o caso, exigir caução real ou fidejussória idônea para ressarcir os danos que a outra parte possa vir a sofrer, com possibilidade de a caução ser dispensada se a parte economicamente hipossuficiente não puder oferecê-la.

A tutela de urgência pode ser concedida liminarmente ou após justificação prévia. A respeito dessa segunda hipótese, Cassio Scarpinella Bueno ${ }^{2}$ também anota que seria esta uma alternativa àquelas situações em que os pressupostos para a concessão da tutela de urgência não são passíveis de demonstração com a própria petição inicial (prova documental, ata notarial ou estudo técnico), sendo o caso, por exemplo, de ouvir testemunhas ou o próprio requerente da medida, o que merece ser justificado na própria petição em que é formulado o pedido. Aqui, o mais correto não é indeferir o pedido de tutela de urgência, mas designar a referida audiência para colheita da prova.

Quando for de natureza antecipada, a tutela de urgência não será concedida quando houver perigo de irreversibilidade dos efeitos da decisão. Essa situação está relacionada ao previsto no art. $273, \S 2^{\circ}$, do CPC/73. A esse respeito vale citar mais uma vez Cassio Scarpinella Bueno, ${ }^{3}$ que expõe entendimento no sentido de que

a vedação da concessão da tutela de urgência nos casos de irreversibilidade não deve prevalecer nos casos em que o dano ou o risco que se quer evitar ou minimizar é qualitativamente mais importante para o requerente do que para o requerido. Subsiste, pois, o implícito ao sistema - porque isso decorre "modelo constitucional" - o chamado "princípio da proporcionalidade", a afastar o rigor literal desejado pela nova regra.

1 BUENO, Cassio Scarpinella. Novo Código de Processo Civil anotado. São Paulo: Saraiva, 2015.

2 BUENO, Cassio Scarpinella. Novo Código de Processo Civil anotado. São Paulo: Saraiva, 2015.

3 BUENO, Cassio Scarpinella. Novo Código de Processo Civil anotado. São Paulo: Saraiva, 2015. 
Portanto, a tutela de urgência poderá ser na forma de cautelar, situação em que se tem autonomia do procedimento, ou de tutela incidental. Em ambos os casos, a ideia é sempre assegurar a utilidade da decisão judicial. Vale ainda ter em mente que, quando de natureza cautelar, a tutela de urgência pode ser efetivada mediante arresto, sequestro, arrolamento de bens, registro de protesto contra alienação de bem e qualquer outra medida idônea para asseguração do direito.

Ademais, independentemente da reparação por dano processual, a parte responde pelo prejuízo que a efetivação da tutela de urgência causar à parte adversa, se: (i) a sentença lhe for desfavorável; (ii) obtida liminarmente a tutela em caráter antecedente, não fornecer os meios necessários para a citação do requerido no prazo de cinco dias; (iii) ocorrer a cessação da eficácia da medida em qualquer hipótese legal; e (iv) o juiz acolher a alegação de decadência ou prescrição da pretensão do autor. Nesses casos, a indenização será liquidada nos autos em que a medida tiver sido concedida, sempre que possível.

Nessas breves palavras, o que se busca é exatamente fincar as bases que guiam a tutela de urgência, a qual, como se verá e já foi sugerido antes, se distingue da tutela de evidência.

\subsection{Tutela de evidência}

A tutela de evidência, por sua vez, está prevista no art. 311 do NCPC e será concedida, independentemente da demonstração de perigo de dano ou risco ao resultado útil do processo, nas situações a seguir.

\subsubsection{Caracterizado o abuso do direito de defesa ou o manifesto propósito protelatório da parte}

Essa possibilidade sugere verdadeira sanção a ser aplicada pelo guardião do processo, o juiz, quando perceber que está havendo verdadeira tentativa de atrasar a análise do caso.

Mas a concessão não está apenas conectada a esse intuito protelatório. É necessário que o direito também esteja presente, ou seja, é indispensável que o autor demonstre claramente que tem razão no pleito de mérito e que o atraso está lhe causando prejuízo. Há autores ${ }^{4}$ que inclusive entendem ser possível a concessão da

4 Nesse sentido: BODART, Bruno Vinícius da Rós. Tutela de evidência: teoria da cognição, análise econômica do direito processual e comentários sobre o novo CPC. 2. ed. São Paulo: Revista dos Tribunais, 2015. (Coleção Liebman). 
tutela de evidência, sob essa situação sancionatória, antes mesmo da apresentação da defesa, uma vez que há casos em que o réu, já ciente do processo, faz de tudo para fugir da citação.

Nas discussões que envolvem a Fazenda Pública, é comum imaginar que tal situação possa ocorrer quando o ente público insiste na discussão de tema já pacificado, sendo o caso mais notório aquele que envolve súmula vinculante. Entretanto, há precedentes em que o judiciário já reconheceu o intuito procrastinador da Fazenda Pública na apresentação de recursos, os quais, mesmo não tratando exatamente da tutela de evidência, demonstram que tal situação não é de exclusividade dos particulares.

Como exemplo de tais precedentes se pode citar decisão do Superior Tribunal de Justiça (STJ) em recurso repetitivo relacionado ao Recurso Especial (REsp) n. 1.035.847, que levou a Fazenda Nacional à condenação. O caso tratava da correção monetária de créditos não escriturais de Imposto sobre Produtos Industrializados (IPI). Nesse caso, houve a imposição de multa em razão da tentativa de se adiar a solução do processo. Outro exemplo é o REsp n. 949.166. Nesse caso, a decisão foi no sentido de que, ao apresentar diversos embargos protelatórios, a União estaria contrariando o interesse público.

Não se está aqui dizendo que necessariamente haveria a concessão da tutela de evidência, de forma incidental, nesses casos, porém tais precedentes sugerem que a Fazenda Pública também pode ser objeto de sanção na situação em que fica evidente o interesse protelatório na apresentação de recursos, o que é premissa para a concessão da tutela de evidência.

\subsubsection{Alegações de fato comprovadas apenas documentalmente com tese firmada em julgamento de casos repetitivos ou em súmula vinculante}

Essa hipótese se baseia na situação em que a alegação é claramente baseada em prova já constituída e a tese defendida está consolidada, tendo sido objeto de julgamento de casos repetitivos ${ }^{5}$ ou súmula vinculante. ${ }^{6}$

5 "Art. 928. Para os fins deste Código, considera-se julgamento de casos repetitivos a decisão proferida em: I - Incidente de resolução de demandas repetitivas; II - Recursos especial e extraordinário repetitivos. Parágrafo único. O julgamento de casos repetitivos tem por objeto questão de direito material ou processual."

6 Constituição Federal, art. 103-A: "O Supremo Tribunal Federal poderá, de ofício ou por provocação, mediante decisão de dois terços dos seus membros, após reiteradas decisões sobre matéria 
Ponto que aqui merece reflexão é o motivo de não ter sido feita referência aos Recursos Extraordinários (RE) julgados pelo Supremo Tribunal Federal (STF) em sede de repercussão geral, que também constituem importantes precedentes. A esse respeito, é interessante a análise do Enunciado 30 aprovado durante seminário ${ }^{7}$ sobre o NCPC realizado pela Escola Nacional de Formação e Aperfeiçoamento de Magistrados (Enfam). Confira-se:

É possível a concessão da tutela de evidência prevista no art. 311, II, do CPC 2015 quando a pretensão autoral estiver de acordo com orientação firmada pelo Supremo Tribunal Federal em sede de controle abstrato de constitucionalidade ou com tese prevista em súmula dos tribunais, independentemente de caráter vinculante.

Outro Enunciado que foi aprovado em tal seminário e merece destaque é o de número 31, o qual prevê que: "A concessão da tutela de evidência prevista no art. 311, II, do CPC/2015 independe do trânsito em julgado da decisão paradigma". Esse entendimento promete ser bastante polêmico, uma vez que o texto legal nada trata sobre tal matéria, valendo anotar, entretanto, que a jurisprudência do STJ, firmada sob a égide do CPC/71, já ditava regra no mesmo sentido.

\subsubsection{Pedido reipersecutório fundado em prova documental adequada do contrato de depósito, caso em que será decretada a ordem de entrega do objeto custodiado, sob cominação de multa}

Ainda que não esteja expressa nessa hipótese, nos parece clara a necessidade da comprovação da mora do devedor. Isso inclusive foi objeto de Enunciado do já mencionado Seminário Enfam, o de número 29, o qual prevê que: "Para a concessão da tutela de evidência prevista no art. 311, III, do CPC 2015, o pedido

constitucional, aprovar súmula que, a partir de sua publicação na imprensa oficial, terá efeito vinculante em relação aos demais órgãos do Poder Judiciário e à administração pública direta e indireta, nas esferas federal, estadual e municipal, bem como proceder à sua revisão ou cancelamento, na forma estabelecida em lei".

7 O seminário foi realizado no período de 26 a 28 de agosto de 2015. A Enfam foi criada pela Emenda Constitucional n. 45/2004 e instituída pela Resolução n. 3/2006 do STJ, e é o órgão oficial de formação de magistrados brasileiros. A ela compete regulamentar, autorizar e fiscalizar os cursos para ingresso, vitaliciamento e promoção na carreira. 
reipersecutório deve ser fundado em prova documental do contrato de depósito e também da mora".

Outro ponto interessante aqui é a previsão de cominação de multa, não havendo qualquer definição do montante. Portanto, nos parece que esta estará sob a definição do julgador, o qual deverá ser guiar pela melhor forma de compelir o devedor ao cumprimento da obrigação.

\subsubsection{Petição inicial instruída com prova documental suficiente dos fatos constitutivos do direito do autor a que o réu não oponha prova capaz de gerar dúvida razoável}

Tendo o autor produzido prova suficiente que evidencia seu direito, e de outro lado o réu não sendo capaz de combater o quanto alegado, exigindo-se que pelo menos cause dúvida, estará o julgador apto à concessão da tutela de evidência, não sendo necessário aguardar o trânsito em julgado da demanda para que o autor tenha acesso ao quanto pleiteado.

Dúvida que se coloca aqui é a robustez da prova apresentada pelo autor, na medida em que a prova definitiva deve ser produzida no próprio processo. Portanto, se está falando de prova que tem o poder de inicial da indução, mas não necessariamente apresenta a certeza, fato que, na prática, poderá levar os julgadores a temerem a concessão dessa tutela. De todo modo, por certo o julgador terá de demonstrar claramente os motivos que levaram à concessão da tutela. Assim, é evidente que a concessão sob essa modalidade estará diretamente conectada à incapacidade da outra parte de fazer prova contrária, ao ser ouvida.

Como se vê, os requisitos para a concessão da tutela de evidência são distintos daqueles exigidos para a outorga da tutela de urgência. Enquanto nesta exige-se a demonstração do perigo de dano ou risco ao resultado útil do processo, naquela esse pressuposto (conhecido como periculum in mora) não está presente. E em que medida a novidade trazida pelo NCPC pode ajudar ainda mais os operadores do direito e os contribuintes em mandados de segurança de natureza tributária? A seguir, procuraremos abordar dois aspectos da questão, não pretendendo esgotá-la.

\section{A TUTELA DA EVIDÊNCIA NO MANDADO DE SEGURANÇA EM MATÉRIA TRIBUTÁRIA}

O Estado é uma sociedade politicamente organizada, dotada de um território, um povo e com objetivos determinados. Inúmeros são os seus deveres, dentre 
os quais se acham a saúde, a segurança, a moradia, a educação, o emprego e o bem-estar social. Para manter essas necessidades básicas da sociedade, o Estado precisa de recursos financeiros e desenvolve atividades para arrecadá-los e geri-los. Tem, assim, assegurado pela Constituição Federal Brasileira, o chamado poder de tributar.

Mas se de um lado o Estado tem esse grande poder, a sociedade tem, de outro, remédios constitucionalmente previstos para a defesa dos seus direitos, no caso de abuso da autoridade estatal. E um desses remédios é inquestionavelmente o mandado de segurança que, sempre vale lembrar, tem por objetivo proteger direito líquido e certo, não amparado por habeas corpus ou habeas data.

Em matéria tributária, o mandado de segurança é medida amplamente utilizada pelos contribuintes que procuram o poder judiciário, porque, em resumo: (i) como regra, esse tipo de ação tem preferência na tramitação; (ii) não é cabível a condenação em honorários de sucumbência; (iii) a sua impetração pode ocorrer tanto em caráter preventivo como repressivo; e (iv) o rito do processo é simplificado, pouco oneroso, e a apelação interposta da sentença concessiva da ordem não impede a sua imediata execução, no caso pelo contribuinte. Além disso, o destaque do mandado de segurança para matéria tributária também reside na possibilidade da concessão de medida liminar que tem o poder de suspender, de imediato, a exigibilidade de qualquer tributo, independentemente de caução, nos moldes do que determina o art. 151, inciso IV, da Lei Federal n. 5.172/1966 (Código Tributário Nacional - CTN).

A inserção da figura da tutela de evidência no ordenamento jurídico pode constituir, a nosso ver, mais um bom atrativo para a adoção do mandado de segurança por contribuintes que pretendam discutir matérias de natureza tributária no poder judiciário. E assim pensamos porque, até a entrada em vigor do NCPC, não havia controvérsia quanto à natureza e ao alcance das medidas liminares concedidas em mandado de segurança envolvendo direito tributário.

Como regra, essas liminares eram enquadradas exclusivamente no capítulo do $\mathrm{CPC} / 73$ destinado às medidas cautelares (não mais existente), ou seja, o provimento jurisdicional delas decorrente era precário, vale dizer provisório. Exemplo disso é o comando insculpido na norma do art. $7^{\circ}, \S 2^{\circ}$, da Lei Federal n. 12.016/2009, que assim dispõe:

Art. $7^{\circ}$. Ao despachar a inicial, o juiz ordenará: [...]

$\int 2^{\circ}$ Não será concedida medida liminar que tenha por objeto a compensação de créditos tributários, a entrega de mercadorias e bens provenientes 
do exterior, a reclassificação ou equiparação de servidores públicos e a concessão de aumento ou a extensão de vantagens ou pagamento de qualquer natureza.

Ou seja, a própria norma legal que disciplina o mandado de segurança impede a prolação de decisões liminares que, de algum modo, conduzam à extinção automática de créditos tributários. Mas, agora, com a entrada em vigor do NCPC e a introdução da tutela de evidência no direito pátrio, parece-nos que houve uma ampliação da eficácia das decisões que têm aplicabilidade imediata, permitindo-se ao magistrado a prolação daquelas inclusive de caráter definitivo.

Sobre a novidade da tutela de evidência, é interessante a posição de Paulo César Conrado, ${ }^{8}$ para quem, das hipóteses constantes do art. 311 do NCPC, a do inciso II é de realçada importância para o direito tributário, ou seja, a que diz respeito à viabilidade da outorga do provimento se "as alegações de fato puderem ser comprovadas apenas documentalmente e houver tese firmada em julgamento de casos repetitivos ou em súmula vinculante".

Outro ponto destacado pelo referido autor é que não há qualquer incompatibilidade entre o mandado de segurança e a tutela de evidência. Para ele, o uso da tutela de evidência não representaria o afastamento da exigência do periculum in mora no mandado de segurança, como se houvesse uma reescritura da lei que rege tal figura processual. Portanto, o mandado de segurança, embora disciplinado em lei própria, deve ser interpretado em contexto com o NCPC, e não isoladamente. Ao assumir essa posição, é necessário ter em mente que a lei do mandado de segurança terá de conviver com o art. 311 do NCPC, o que nos parece bastante razoável, exatamente no que tange ao inciso II, já que nessa situação nos parece que não haveria dúvida do direito líquido e certo a ser defendido pelo autor.

Contudo, no caso do inciso II do art. 311 do NCPC o julgador terá de conviver com a necessidade de verificar se a prova pré-constituída está em linha com a tese consolidada. Isso não significa que no mandado de segurança haverá uma fase probatória, mas apenas a evidência de que o direito é líquido e certo. Assim, o julgador deverá estar aberto a essa situação, e não meramente ignorá-la sob a alegação de que no mandado de segurança não cabe análise de prova, pois se assim fosse não haveria certeza do direito líquido e certo.

8 CONRADO, Paulo César. Site Consultor Jurídico. 25 maio. 2016. 
Vale ainda registrar que o NCPC não delimita os efeitos da decisão proferida em tutela de evidência, sendo admissível afirmar, em nossa opinião, que essa medida também teria natureza definitiva, especialmente por ser concedida nos termos do referido inciso II do art. 311, ou seja, casos com tese fundada em julgamento de casos repetitivos ou em súmula vinculante. Essa, seguramente, é uma inovação importante porque, com esteio em um precedente tomado pelo STJ em sede de Recurso Especial Repetitivo representativo de determinada controvérsia ou súmula vinculante, um contribuinte poderá, em tese, pleitear não só a suspensão da exigibilidade de um crédito tributário, mas a sua própria extinção, o que lhe dará o direito, por exemplo, inclusive de obter Certidão Negativa de Débitos (CND) e não mais Certidão Positiva com Efeitos de Negativa (CPEN).

Sobre essa matéria, é interessante a lição do Ministro Luiz Fux, ${ }^{9}$ que presidiu a comissão de juristas que elaborou o anteprojeto do NCPC, para o quem o "direito evidente é aquele em que se tem algo além do fumus boni iuris, sendo equiparável ao direito líquido e certo do mandado de segurança”." O referido autor parte do princípio de que a decisão que concede a tutela de evidência é fundada em cognição exauriente, e não em cognição sumária. Segundo o ministro da mais alta corte brasileira, "a evidência do direito exclui a cognição sumária, porque é o próprio objeto litigioso que se oferece completo ao juízo".

Agora é esperar para ver como vai se consolidar a jurisprudência sobre a matéria, valendo lembrar que, quando da introdução do instituto da tutela antecipada no $\mathrm{CPC} / 73$, as primeiras decisões que foram proferidas pelo poder judiciário fixavam a tese de que esse tipo de tutela não era aplicável contra a Fazenda Pública. Mas, com o passar do tempo, houve uma reversão no entendimento e hoje se acham julgados proferidos em sentido inverso, como é o caso da conclusão que se alcançou no julgamento do REsp n. 770.308/SC, cuja ementa é reproduzida:

PROCESSUAL CIVIL. TRIBUTÁRIO. ICMS. SUSPENSÃO DE EXIGIBILIDADE. ANTECIPAÇÃO DE TUTELA CONTRA A FAZENDA PÚBLICA. POSSIBILIDADE.

1. Desde que preenchidos os respectivos pressupostos, não há óbice à concessão de tutela antecipada contra a Fazenda Pública.

2. Recurso especial provido. (REsp n. 770.308/SC, Rel. Min. Eliana Calmon, $2^{\text {a }}$ Turma, julgado em: 11 set. 2007)

9 FUX, Luiz. Tutela de segurança e tutela da evidência: fundamentos da tutela antecipada. São Paulo: Saraiva, 1996. p. 305. 
Outra vantagem trazida pela tutela de evidência é que ela, como já visto neste artigo, dispensa a verificação do perigo na demora. Nos tempos atuais, para a outorga da tutela de evidência, não é necessário demonstrar o risco de dano irreparável ou de difícil reparação. É suficiente asseverar, de acordo com o art. 306, que o direito é evidente.

É lógico que a tutela de evidência deve respeitar o princípio do contraditório. Assim, nesses casos, como não há a urgência no reconhecimento do direito, o réu (no caso, a Fazenda Pública) deve ser ouvido previamente. Ou seja, nas hipóteses de evidência que envolvam matérias exclusivamente de direito, o contribuinte pode esperar pela resposta do réu, que poderá trazer elementos relevantes para a correta solução da lide e a sua extinção imediata do processo, com julgamento de mérito e sem a interposição de recursos meramente protelatórios.

Ainda sobre a tutela de evidência, embora, como dito, seja necessário aguardar a consolidação da jurisprudência sobre a matéria, já é possível encontrar alguns julgados no sentido da sua aplicabilidade nas lides envolvendo a Fazenda Pública, desde que cumpridos os seus requisitos, como se verifica do seguinte Acórdão do Tribunal de Justiça do Distrito Federal e Territórios: ${ }^{10}$

10 No mesmo sentido: "Ementa: AGRAVO DE INSTRUMENTO. CONTRATO ADMINISTRATIVO. IMPOSIÇÃO DE PENALIDADE DE MULTA. AÇÃO ANULATÓRIA. TUTELA PROVISÓRIA CONTRA A FAZENDA PÚBLICA. INTERPRETAÇÃO RESTRITIVA DAS VEDAÇÕES CONTIDAS NA LEI 9.494/97. TUTELA DE EVIDÊNCIA. HIPÓTESE REQUERIDA QUE NÃO AUTORIZA DEFERIMENTO ANTES DE OPORTUNIZADO O CONTRADITÓRIO. - O Supremo Tribunal Federal, em que pese ter sufragado a constitucionalidade das vedações contidas na Lei no 9.494/97, entende que somente não pode ser deferida tutela provisória em desfavor da Fazenda Pública nas hipóteses que importem em: (a) reclassificação ou equiparação de servidores públicos; (b) concessão de aumento ou extensão de vantagens pecuniárias; (c) outorga ou acréscimo de vencimentos; (d) pagamento de vencimentos e vantagens pecuniárias a servidor público ou (e) esgotamento, total ou parcial, do objeto da ação, desde que tal ação diga respeito, exclusivamente, a qualquer das matérias acima referidas. - No caso, é possível, em tese, a concessão da tutela de evidência pretendida, porque, além de não envolver reclassificação, equiparação, concessão de aumentos ou vantagens a funcionários, a eventual concessão não esgotará, total ou parcial, o objeto da ação, já que a parte agravante pretende somente que o agravado se abstenha de inscrever o valor da penalidade aplicada em dívida ativa e que promova a execução fiscal. - Contudo, a concessão da tutela provisória de evidência só admite concessão inaudita altera parte quando (i) as alegações de fato puderem ser comprovadas apenas documentalmente e houve tese firmada em julgamento de casos repetitivos ou em súmula vinculante (inc. II); ou (ii) se tratar de pedido reipersecutório fundado em prova documental de contrato de depósito (inc. III). Nas outras duas hipóteses (incs. I e IV do art. 311 do NCPC), em razão do disposto no parágrafo único, a concessão dependerá 
CIVIL E PROCESSUAL CIVIL. AGRAVO DE INSTRUMENTO. VARA DA FAZENDA PÚBLICA. DEMANDA DECLARATÓRIA DE INEXISTÊNCIA DE RELAÇÃO JURÍDICO TRIBUTÁRIA. TUTELA DE URGÊNCIA. INDEFERIMENTO. DECISÃO MANTIDA.

1. Prescreve o artigo 311, II, do NCPC que a tutela da evidência será concedida, independentemente da demonstração de perigo de dano ou de risco ao resultado útil do processo, quando as alegações de fato puderem ser comprovadas apenas documentalmente e houver tese firmada em julgamento de casos repetitivos ou em súmula vinculante, hipótese na qual é lícito ao magistrado deferir liminarmente o pedido se presentes os requisitos (artigo 311, parágrafo único, novo Código de Processo Civil).

2. A tutela de evidência somente ocorre quando o legislador desde logo presume que a defesa será inconsistente (art. 311, II e III, CPC). [...] Nos demais casos a concessão de tutela de evidência só pode ocorrer depois da contestação (MARINONI. LUIZ GUILHERME. Novo Código de Processo Civil comentado. 2. ed. São Paulo: RT, 2016, p. 394).

3. Se a instrução probatória se faz necessária para definir o valor que o agravante pretende ver compensado, bem como se há necessidade de produção de prova pericial, tais fatos já são impedimento para a concessão da tutela postulada por contrariar o requisito da comprovação exclusivamente documental. Ademais, se a questão ainda não se encontra pacificada no âmbito da Suprema Corte, resta afetado o segundo requisito para a concessão da tutela de evidência.

4. Agravo conhecido e desprovido. (Acórdão n. 956845, 20160020108843AGI,

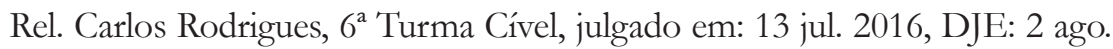
2016)

Também já é possível encontrar julgados entendendo cabível a aplicação, cumpridos os seus quesitos, da tutela de evidência em mandado de segurança:

DIREITO ADMINISTRATIVO. MANDADO DE SEGURANÇA. INSS. LIMITAÇÃO AO EXERCÍCIO PROFISSIONAL. EXIGÊNCIA DE

da atitude a ser tomada pela parte contrária, quer dizer, somente após angularizada a relação processual é que o juiz estará autorizado a conceder a tutela de evidência. - Na espécie, a tutela de evidência (fundada no inciso IV do art. 311 do NCPC) é descabida, pelo simples fato de que se deve aguardar a manifestação do réu. Agravo desprovido" (Tribunal de Justiça do Rio Grande do Sul, Al n. 70070362934, 22ª Câmara Civel, Rel. Marilene Bonzanini, julgado em: 13 out. 2016. 
PRÉVIO AGENDAMENTO PARA ATENDIMENTO DO ADVOGADO. IMPOSSIBILIDADE. SUJEIÇÃO AO SISTEMA DE FILAS E SENHAS. TESE CONSOLIDADA NESTA CORTE. AUSÊNCIA DE SÚMULA VINCULANTE OU JULGAMENTO DE RECURSO REPETITIVO. TUTELA DE EVIDÊNCIA INDEFERIDA. APELO PARCIALMENTE PROVIDO. [...]

3. Tutela de evidência indeferida. Ausência de tese firmada em julgamento de recurso repetitivo ou súmula vinculante a amparar o pleito do apelante, nos termos do artigo 311, inciso II do CPC/15.

4. Apelação parcialmente provida. (TRF $3^{a}$ Região, $3^{\text {a }}$ Turma, AMS n. 364225 0007233-10.2015.4.03.6109, Rel. Desembargador Federal Nery Junior, julgado em: 22 mar. 2017, e-DJF3: 31 mar. 2017)

O tempo permitirá que se verifique a consolidação da matéria pelos tribunais país afora, sobretudo após a questão passar pelo crivo das cortes superiores. Nesse estágio, com o curto período de vigência do NCPC, já se viu que alguns tribunais admitem a tutela de evidência nas lides tributárias e, adicionalmente, que a tutela também é admitida em sede de mandado de segurança. Espera-se que o saldo final seja no sentido de se permitir a tutela de evidência em mandados de segurança envolvendo discussões tributárias, visto que a possibilidade, além de permitir que o judiciário se desafogue de processos, julgando mais velozmente as lides que lhe são submetidas, é um mecanismo que facilita o direito de defesa dos contribuintes, que já têm de arcar com a elevada carga tributária do país.

\section{CONSIDERAÇÕES FINAIS}

Neste artigo, procuramos demonstrar, em poucas palavras, a situação em que se acha o sistema tributário nacional e a importância da efetividade das decisões proferidas pelo poder judiciário. Para nós, as decisões exaradas em caráter acautelatório e imediatamente exauriente são de suma importância para resguardar os direitos dos contribuintes, sejam eles pessoas físicas ou jurídicas. E o NCPC veio trazer mais uma luz sobre o assunto, com a introdução da chamada tutela de evidência.

Esse instituto seguramente trouxe um avanço para o controle da legalidade e da constitucionalidade das normas tributárias editadas pelos entes da federação e, além disso, tem potencial para combater a morosidade de nosso judiciário. E esperamos que todos interpretem a novidade de maneira aberta e não restritiva, já que esse certamente foi o espirito do legislador ordinário ao instituir o NCPC. 
Unindo-se o mandado de segurança a essa nova modalidade de tutela, talvez se consiga proteger o direito líquido e certo de forma muito mais ágil, já que também concede mais segurança a quem decide. Resta aguardar a pacificação da matéria pelos tribunais. Caso aquiesçam com a possibilidade, os benefícios não se cingirão apenas aos contribuintes, no que toca ao seu direito de defesa, mas também ao próprio judiciário, visto que se abre uma possibilidade de os processos tributários serem julgados com maiores celeridade e segurança. 